NBER WORKING PAPER SERIES

\title{
A RICARDIAN-DEMAND EXPLANATION FOR CHANGING PHARMACEUTICAL R\&D PRODUCTIVITY
}

\author{
Mark Pauly \\ Kyle Myers \\ Working Paper 22720 \\ http://www.nber.org/papers/w22720 \\ NATIONAL BUREAU OF ECONOMIC RESEARCH \\ 1050 Massachusetts Avenue \\ Cambridge, MA 02138 \\ October 2016
}

We are grateful to the Pharmaceutical Research and Manufacturers of America for providing data that enabled our analyses. We are also thankful for the thoughtful comments and suggestions from Joe DiMasi, Pierre Dubois, Neeraj Sood and other attendees at the 2016 Bates White Life Science Symposium. The views expressed herein are those of the authors and do not necessarily reflect the views of the National Bureau of Economic Research.

NBER working papers are circulated for discussion and comment purposes. They have not been peer-reviewed or been subject to the review by the NBER Board of Directors that accompanies official NBER publications.

(C) 2016 by Mark Pauly and Kyle Myers. All rights reserved. Short sections of text, not to exceed two paragraphs, may be quoted without explicit permission provided that full credit, including () notice, is given to the source. 
A Ricardian-Demand Explanation for Changing Pharmaceutical R\&D Productivity

Mark Pauly and Kyle Myers

NBER Working Paper No. 22720

October 2016

JEL No. D20,I11,L10,L65,O31

\begin{abstract}
$\underline{\text { ABSTRACT }}$
This paper examines trends in the aggregate productivity of the pharmaceutical sector over the past three decades. We incorporate Ricardo's insight about demand-driven productivity in settings of variable scarce resources, and estimate the industry's responsiveness to changes in demand over this timeframe using therapeutic class-specific data. In contrast to many analyses, our empirical estimates indicate that the industry has "met demand" with remarkable consistency since the late-1980s. The growth in total R\&D spending, and therefore R\&D costs per new drug, appear to have been profitable and productive investments. While we identify a significant increase in the industry's fixed costs - the intercept of the production function - we find no decline in the marginal productivity of industry investments that might suggest significant supply-side frictions. While we cannot diagnose in detail why average, but not marginal, productivity declined, the data suggests that firms have finally begun to compete down returns from the supranormal levels of decades past.
\end{abstract}

\author{
Mark Pauly \\ Health Care Management Department \\ The Wharton School \\ University of Pennsylvania \\ 208 Colonial Penn Center \\ 3641 Locust Walk \\ Philadelphia, PA 19104-6218 \\ and NBER \\ pauly@wharton.upenn.edu \\ Kyle Myers \\ Health Care Management \\ \& Economics Department \\ The Wharton School \\ University of Pennsylvania \\ 4th Floor, Colonial Penn Center \\ 3641 Locust Walk \\ Philadelphia, PA 19104-6218 \\ myersky@wharton.upenn.edu
}

A data appendix is available at http://www.nber.org/data-appendix/w22720 


\section{Introduction}

Considerable criticism has been expressed about the research and development process for new drugs since at least the 1990s. Compared to those years, estimates of private R\&D cost per new drug that makes it to market have been high and rising rapidly, more than tripling. The volume of new drugs was flat for much of the period. While it is hard to construct a price index for a mix of new products, there certainly have been complaints about the prices of those new products. The perception of limited introduction of truly novel drugs procured at dizzying research costs and sold at surprisingly high prices have led to feelings of malaise on the part of the industry and feelings of outrage by its $\operatorname{critics}^{1}$. Despite a little improvement recently, the drug development model has broken, people say, but there is no generally accepted account of why and how, and what if anything to do to put it back together again. Maybe it was the FDA's fault for restrictive and costly rules and procedures. Maybe it was the failure of firm management in managing the discovery process as well as it had in the past, as science changed in way that required adaptation. Maybe scientists were preoccupied with publication and grant financing. Maybe the number of good ideas in science were as numerous and attractive as ever, but there was some kind of glitch in translating them into clinically useful products (Scannell et al. 2012).

In this paper we try to explain what happened (and to some extent deflect this blame game) by using new disaggregated data on NIH and US private firm R\&D investment across time and across therapeutic categories to establish the relationship between these two sources of inputs for drug discovery and development and the associated output in terms of New Medical Entities (NMEs): a new drug production function. Our best data are for the years up to 2000, but we extend the analysis to 2013 with our empirical approach. We begin with a simple production function and use it to estimate the marginal NME product of each type of spending. We then tell a story about those estimates that draws on a demand side explanation for both investments in new products and their R\&D costs.

Disaggregated data on firm investments across therapeutic categories enables us to estimate the relationship between private $R \& D$ investment and (1) exogenous shifts in potential market size driven by demographic trends as suggested by Acemoglu and Linn (2004), and (2) prior investments in basic research at the National Institutes of Health (NIH). These two factors alone an explain a substantial proportion, nearly $90 \%$, of the variation in R\&D investments within each category, and predict a private marginal cost per new molecular entity

\footnotetext{
${ }^{1}$ See for example, Hewitt, Campbell \& Cacciotti. Beyond the shadow of a drought: the need for a new mindset in pharma RESD. Oliver Wyman, 2011.
} 
(NME) in line with previous estimate for this time period.

We assume that there are two inputs into the production of NMEs of a particular category (such as cancer, cardiovascular, etc.): spending on research by NIH institutes, and spending on R\&D by private firms. NIH spending may sometimes be thought of as a public good, developing information useful for many new products at near-zero marginal cost per additional user. But not all NIH research necessarily is a public good in the non-excludable sense, because NIH funding of university research can become intellectual property for the university or its assignees under the Bayh-Dole act, with no repayment to the taxpayers who funded the research. Conversely there is nothing to prevent a private firm from supporting basic research as well as applied research. Finally, not all spending in both sectors supports clinical research (rather than marketing or community outreach). While our data on these inputs may over- or under-estimate their true values for these reasons, we are mainly concerned with changes in the relationships within our model. Thus, bias will only arise if our measurement errors are correlated with other factors of the model and persist conditional on our controls.

We also explore the impact of private spending. If it is random and uncorrelated with public investments, it will not affect the estimated productivity of NIH spending and will itself have an unbiased coefficient. But there are strong reasons to think that firms respond to NIH findings, and this we explore in considerable detail. In addition, we assume, in the spirit of Acemoglu and Linn (2004), that private investment responds to the "size of the market" (specifically, potential annual gross revenues) for particular categories of drugs in particular time periods. Managers will have expectations about the future of certain therapeutic markets, and will allocate their investments accordingly. After first treating private spending as an included exogenous variable, we then explore the consequences?both for measures of NIH productivity and private firm productivity? of treating private spending as endogenous. Along the way we consider the interesting question of whether NIH spending has a positive or inverse effect on private spending. However, for the most policy relevant time period we would like to study, post-2000 compared to pre- we only have aggregated industry $\mathrm{R} \& \mathrm{D}$ data, which prohibits a more straightforward analysis. To overcome this limitation and attempt to diagnose the changes observed in this timeframe, we generate estimates of predicted private R\&D spending as a function of future demand and prior NIH spending. We then use those predicted values to estimate the production function for the second half of the period?where we are especially interested in changes in NIH and private R\&D productivity. We interpret these descriptive empirical results in terms of a model of the supply of and demand for investment in new drugs, with special emphasis on the role of 


\section{Figure 1: Private NME R\&D Investments: Actual and Pre- dicted}

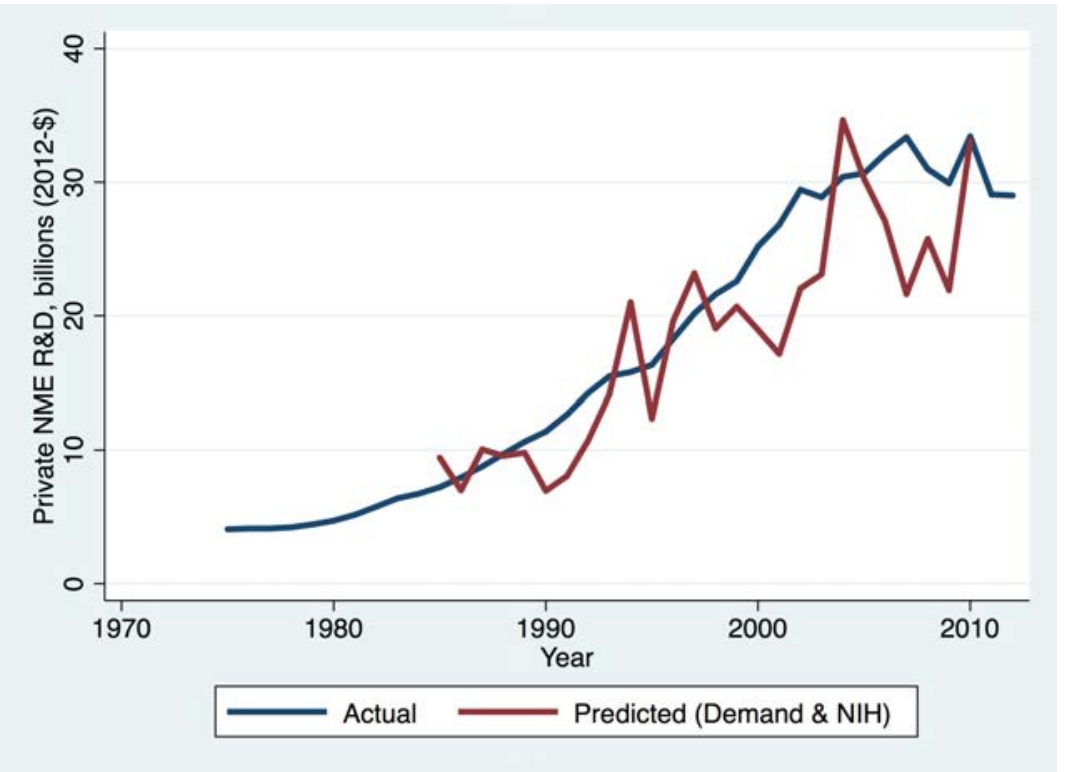

Note: Actual spending data based on estimates of (1) total U.S. domestic R\&D and (2) share of R\&D for New Molecular Entities (NME) from PhRMA annual reports. Predicted R\&D is based on the relationship between potential market size and NIH spending estimated with pre-2001 data.

consumers' willingness to pay for new drugs.

Figure 1 shows the accuracy of our predictive model (described in detail below); it plots the sum of these predicted values alongside actual aggregate spending to illustrate the significant role of potential demand and basic science in generating private investments. The figure also highlights the scope of our analyses - we can only explore changes in the productivity of R\&D dollars invested in response to the industry's major forces of supply and demand. Still, our results speak to the productivity of "real" R\&D at the firm, irrespective of changes in regulations or other external industry-wide shocks that influence costs or production beyond the R\&D phase. The accuracy of prediction clearly drops after 2000 (often under-predicting private $R \& D)$ but still remains reasonably close in terms of trend. That firms invested more than was predicted while the rate of NME approvals remained flat is suggestive of one type of productivity decline in this period (drugs per R\&D dollar), however, these may still have been optimal investments from firms' perspectives if the growth in future demand suggested firms would remain productive in generating economic profits (returns per R\&D dollar) even at lower rates of new drug productivity. 


\section{Theoretical Motivation: David Ricardo and Produc- tive Ideas}

One of the major contributions of the economist David Ricardo was the distinction between price mechanisms for different kinds of production inputs. Ricardo argued the productivity of agriculture depended on the type of input. Most inputs (e.g. seed, animals) had their prices determined by the marginal cost of producing them, and in turn affected the price of crops. But the price of land (rent) was a different story; in this case, rather than the price of the final output being "cost determined," it was more correct to say that its price or cost per unit was determined by the price of the final product, itself a function of demand. The simple notion is that the stock of arable land is exogenous (or at least fixed in the short run) but its price is determined by demand. His key insight for our purposes is that, as increases in demand bring more, less fertile, land into production, productivity will necessarily decline. That decline is an inevitable result of moving on to the set of next most profitable opportunities. Indeed, in this model with supply of opportunities fixed and growing demand, increases in demand must result in declining measured productivity with no person or institutional change being at "fault".

We propose a similar process determining the R\&D cost per new drug. Our implied theoretical model is as follows: exogenous inputs, namely public investments in basic science and demographic-driven demand growth, determine the distribution of new drug ideas per their expected profitability. An increase in demand that may arise from growth in population size, income or insurance coverage will increase the return on investment across all potential drug opportunities, causing ideas with costs too high to justify investment under prior (lower) demand to become potentially profitable. But importantly, unless these demand shocks are accompanied by equal growth in the supply (or quality) of these ideas, these newly profitable ideas have the same lower expected productivity (higher costs) from when demand was lower.

That is, increasing the output of new drugs in response to demand increases has to lower the productivity of R\&D when inputs are scarce - without anyone being at fault, without any evildoers creating glitches, scientists being distracted, and without any industry's R\&D model breaking. Unless there is an equivalent offset in the number or quality of ideas - a scientific discovery or a surge in NIH investments - increasing R\&D costs per new product is an expected fate in a world with growing demand. The movement to "high hanging fruit" is not bad luck; it is a result of firms' rational investment decisions. Figure 2 illustrates this distribution of $R \& D$ opportunities and how the optimal investment decision changes as 


\section{Figure 2: Illustrative count of drug candidates and the role of demand and costs}

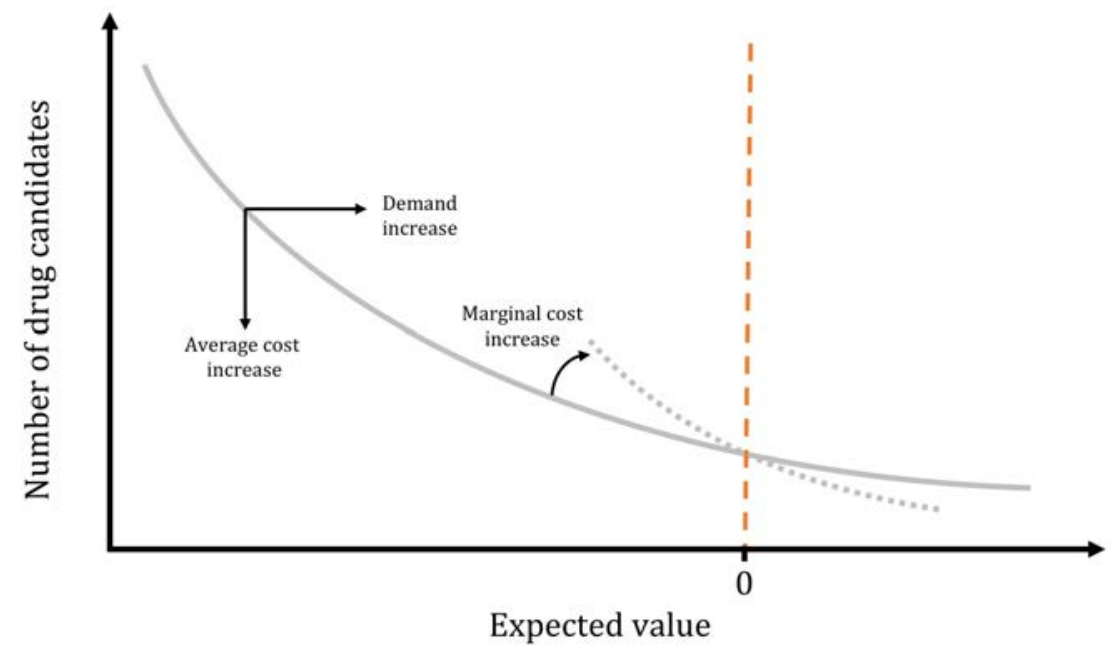

demand and costs determine the expected profits associated with each potential new drug. The figure shows a distribution of new drug ideas by their expected value based on expected revenues and costs $($ Expected Value $=($ Expected Revenues $\times$ Success Rate $)-$ Expected Costs).

Our underlying intuition is that firms observe this distribution and select profitable ideas (Expected Value $>0$ ) to commercialize. In practice, this amounts to monopoly rents being competed away post patent expiration. However, this distribution can be "restocked" in the sense that investments in basic research can change the number and/or quality of the ideas. Thus, the distribution represents the quality of ideas at a fixed point in time. Our empirical analyses will explore year-to-year changes in its shape. With information on the shape and evolution of this distribution one could predict both the number of new products (the number of ideas multiplied by the average success rate conditional on the Expected Value $>0$ ) and expected net revenues (the sum of success rates multiplied by revenues for Expected Value $>0$ ).

Holding costs constant, an increase in total demand will shift the distribution to the right as larger expected revenues increase the value of all ideas. Now, ideas previously unprofitable because of high costs relative to revenues are chosen for investment. Without any changes to the productivity of an industry increases in demand will spur higher spending on the research and development of new products.

Conditional on demand, changes in the expected costs (success probability times actual costs) 
can affect the distribution in two important ways. Increases in the costs of the marginal project will shift the slope of the distribution downward, while increases in the average costs across all projects (which includes any fixed costs of having a non-zero number of projects) will shift the intercept of the distribution downward, and vice versa for decreases in these costs. Diagnosing the productivity of this industry is, in effect, identifying what (if anything) happened to the shape of this distribution.

To be clear, this figure depends on the productivity (profitability) of the marginal and average R\&D idea and not the marginal or average productivity of each R\&D dollar. However, project-level data of any industry is extremely difficult to obtain and in this paper our data on firm investments are aggregated to the therapeutic-class level. Thus, our empirical estimates will be based on changes in the total dollars invested within each class over time and will technically identify the average and marginal productivity of R\&D dollars. But given the high fixed costs of pharmaceutical R\&D that we are measuring, we will instead interpret our results as providing insight into changes over time in the productivity of the average and marginal ideas.

What drives differences in the costs associated with these ideas? Looking across ideas, recent work from Budish et al. (2015) highlights the importance of variation in the costs across projects for different types of cancers and find evidence of distortions away from research on early-stage cancers, which have a larger clinical trial costs ${ }^{2}$. Looking across time, increases in the length and complexity of clinical trials, which would decrease the average profitability of ideas, has been observed over the past decades. Regulatory burdens such as longer approval times and larger post-marketing surveillance efforts have also been cited as sources of larger total (average) costs in the industry (Kola and Landis 2004).

In terms of the farmers first studied by Ricardo, comparing the productivity of the marginal and average new drug opportunity is analogous to evaluating whether increases in demand encouraged farmers to seek out land that was less fertile (decreasing productivity of the marginal idea) or incur higher fixed costs of transporting crops to market (decreasing productivity of the average idea).

This distinction of marginal and average costs is essential for understanding how certain policies will influence production in this industry. For example, R\&D tax subsidies typically offset marginal R\&D expenditures (since they're granted as a share of expenditures), while market exclusivity provisions and other prizes in effect reduce the average (fixed) costs of

\footnotetext{
${ }^{2}$ Because the clinical trials must follow patients for much longer to reach clinical endpoints. The authors also discuss the role of "short-termism" whereby agency problems in the management process induces inefficient discounting that incentivizes the pursuit of shorter clinical trials (Budish et al. 2015).
} 
eligible trials. Some policies, such as the Orphan Drug Act, operate on both margins in that they provide prizes (exclusivity) and subsidies (tax breaks). Despite this importance, delineating between these two margins does not appear to occur regularly in policy debates or analyses of the pharmaceutical industry. In diagnosing this industry, we will make clear where our estimates indicate changes have occurred, on average or the margin. Figure 3

\section{Figure 3: Identifying production shocks amidst demand growth}
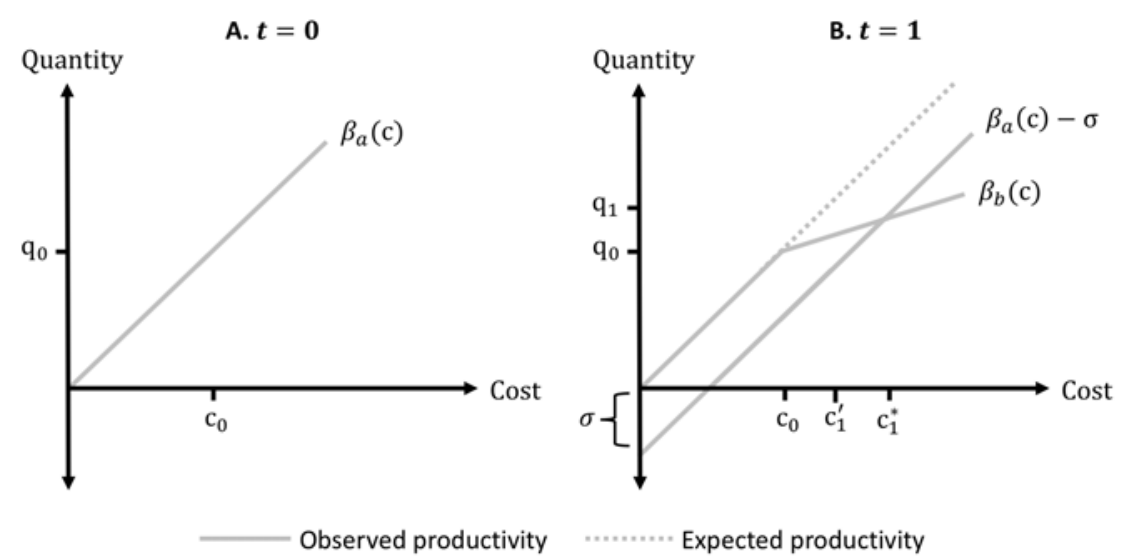

provides a visual depiction of the empirical analysis as it pertains to the distribution of ideas presented in Figure 2. Consider a monopolist firm who observes demand and sets production $\operatorname{costs} c$ which determine quantity produced $q$ per $q=\beta(c)$. Demand at time $t=0$ determines the optimal quantity $q_{0}^{*}$. As researchers, we observe $c_{0}$ and $q_{0}$, and then by assuming that firms optimally invested in $\mathrm{R} \& \mathrm{D}$ given their expectations of demand can recover an estimate of the productivity parameter at this time, denoted $\beta_{a}$.

Now consider the next time period $t=1$ where the optimal quantity to deliver is $q_{1}^{*}$, and we researchers observe $c_{1}^{*}$ (Figure $3 \mathrm{~B}$ ). Because $c_{1}^{\prime}$ is less than $c_{1}^{*}$, we can infer that the distribution of ideas presented in Figure 2 has changed. Here, $\sigma$ (the intercept) captures any level changes in the distribution, while the difference between $\beta_{a}$ and $\beta_{b}$ captures any change in the slope of the distribution. As drawn, the two production functions in $t=1$ achieve $q_{1}$ for the same total (average) costs. While this is certainly a unique case, it demonstrates that when observed in the cross-section it is impossible to discern average versus marginal changes in the productivity of ideas, the goal of our exercise. This motivates our use of only within-drug category variation in order to condition out time invariant differences across drug classes. 


\section{Empirical Production Function}

We model the number of NMEs approved by the FDA in therapeutic category $j$ in time $t$ as a reduced form conditional Poisson model as

$$
\mathrm{NME}_{j t}=\frac{\exp \left(\beta \mathbf{X}_{j t}+\sigma_{t}\right)}{\sum_{\tau=t} \exp \left(\beta \mathbf{X}_{j \tau}+\sigma_{\tau}\right)}+\epsilon_{j t}
$$

where $\mathbf{X}_{j t}$ is a vector of category-time specific inputs to the production process and $\sigma_{t}$ are industry-wide shocks to average productivity. This formulation accommodates the count nature of our dependent variable while conditioning out time-invariant differences across therapeutic categories (e.g. fixed costs of a clinical trial). These average differences appear to be substantial, accounting for roughly $30 \%$ of the observed variation in NME output and nearly $80 \%$ of the observed variation in private R\&D spending across therapeutic categories $^{3}$.

We begin by assuming that our two main production determinants of $\mathbf{X}_{j t}$ are (1) lagged private $R \& D$, and (2) lagged public basic science are exogenously determined, and estimate our main equation (1).

Importantly, some models will be presented without time period fixed effects to inform calculations of the implied marginal products per each input. Such "cost per NME" calculations, which are intended to inform managers and policymakers, should not control for industrywide trends because the influence of such trends on the dependent variable is part of the main story. Any estimates of costs based on elasticities estimated in models demeaned by (statistically significant) time trends is likely to over- or underestimate productivity if aggregate productivity is decreasing or increasing, respectively. Moreover, at least as far as $\mathrm{NIH}$ spending is concerned, spending in one clinical category may have positive effects on productivity in other categories (e.g., the research that lead to Avastin a cancer drug also led to Lucentis an eye drug).

Private firms were likely not funding $R \& D$ projects at random even in the period of low productivity, but are rather responding strategically to prior investments in basic science, future expectations of demand and their consequences for profits in excess of normal economic profits. And because we cannot identify exogenous firm characteristics, estimating equation (1) including private spending along with the supply of science and ignoring the demand for

\footnotetext{
${ }^{3}$ These estimate are from log transformed OLS models with therapeutic category fixed effects, since coefficients of these effects are not estimated in the conditional Poisson specification. Although these specifications are obviously biased, they provide a sense of the magnitude of these effects.
} 
certain types of drugs would confound firm-level and endogenous market-level characteristics, biasing our estimates of $\beta$.

Hence, we also write a two-stage model of investment decisions and production where private R\&D in class $j$ at time $t$ is determined by market-level characteristics $\mathbf{S D}_{j t}$ that include our demand measure and NIH spending

$$
\log \left(\mathrm{R} \& \mathrm{D}_{j t}\right)=\beta_{0}+\beta_{\mathbf{S D}} \mathbf{S D}_{\mathbf{j t}}+\delta_{j}+\mu_{t}+\varepsilon_{j} t
$$

which in turn determines NME output within classes over time per

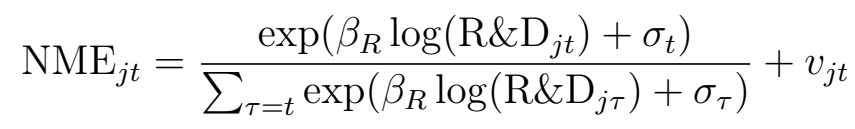

When disaggregated data on private spending is available, we can estimate a joint variant of these equations using instrumental variables via Generalized Method of Moments as outlined by Blundell et al. $(2002)^{4}$.

Given our data limitations of lacking post-2000 category specific investments (described below), we will also implement a two-step version of these equations under the assumption that the causal effects of supply and demand conditions estimated in the first stage $\left(\beta_{\mathbf{S D}}\right)$ are persistent. Then, substituting predicted private R\&D into the second equation, we can test for significant changes in $\beta_{R}$ post-2000 which would indicate productivity changes. Furthermore, we can still test whether or not public investments in basic science have any direct effect on NME output beyond their ability to stimulate private investment.

It is worth noting that a key determinant of investment beyond forces of supply and demand (per $\mathbf{S D}_{\mathbf{j t}}$ ) is firms' expectations about their own production functions, $\beta_{r}$ and $\sigma_{t}$. Changes in expectations about these parameters would be captured in our model by the $\mu_{t}$ term in equation (3). For example, if firms knew in advance that was to change in future periods, perhaps due to frictions in the labor market, and responded by changing investments across all categories, then this would manifest in $\mu_{t}$. However, we cannot estimate these time-period fixed effects for years we lack disaggregated investment data.

Therefore any changes in $\beta_{r}$ or $\sigma_{t}$ that we identify post-2000 are related to changes only in the productivity of the private R\&D instrumented by our measures of supply and demand. We do not know whether there were unobserved industry-wide forces that prompted firms to invest additional amounts in R\&D beyond what was predicted by the pre-2000 model.

\footnotetext{
${ }^{4}$ We kindly thank Timothy Simcoe for making a STATA implementation of this procedure available on his website at http://people.bu.edu/tsimcoe/data.html.
} 
It is plausible there were unrealistically optimistic expectations of success. Supply side changes, like changes in FDA policies that made approval unexpectedly less likely, might also come have into play. If such changes in policy had been expected so that anticipated profits were reduced, that should have led to cutbacks in investment (or at least a slowing of growth relative to trend), something that did appear to have happened (see Figure 1). In fact, $R \& D$ investments grew at a rate greater than we might have expected given firms' estimated responsiveness to the NIH and consumers' demand. Later, we hypothesize reasons underlying this discrepancy, including a decline in abnormal industry profits and a feature of our demand measure that does not take the rising value of health into account ${ }^{5}$. Still, the variation we can explore is important because it speaks directly to real R\&D dynamics induced by market-wide forces, regardless of changes to the industry-specific environment. Thus, although this is a study of pharmaceutical productivity, we are examining variation likely the most generalizable to other industries.

\section{Data Construction}

This section describes our main data sources and how they were utilized to construct our four key variables: private pharmaceutical R\&D, exogenous potential demand (per Acemoglu and Linn (2004)), NIH investments in basic science, and New Molecular Entities approved by the FDA; as well as how we determined the structure of our sixteen therapeutic categories.

\subsection{Drug Categories \& FDA Approvals}

Determining the specificity of drug categories for our empirical analysis is a tradeoff between the ability to control for important (more delineated categories) versus allowing for spillovers given the idiosyncratic nature of R\&D (fewer broad categories). Although private R\&D investments are only available for eight drug categories as detailed below, the demand and $\mathrm{NIH}$ data can more easily be decomposed into more specific categories.

Using the Anatomical Therapeutic Class (ATC) categorization scheme as a guide, we matched the eight industry R\&D categories to the most obviously corresponding sixteen subgroups

\footnotetext{
${ }^{5}$ The potential demand measure holds the income elasticity of demand for new spending and new technology fixed at one. There is good evidence that this elasticity is in fact both greater than 1 and possibly increasing over time (Hall and Jones 2007). In fact, the estimates considered by Hall and Jones (2007) are large enough to plausibly explain the full gap in R\&D investment we observe.
} 
of the ATC hierarchy as shown in the Appendix (Table $\mathrm{A} 1^{6}$.

The real outcome we are concerned with is welfare changes as a result of new products released by the pharmaceutical industry. Because data necessary to calculate welfare is rarely available (i.e. drug-specific revenues and quality-adjusted life years generated), it has become common practice to evaluate the count of new drugs approved. Obviously a raw count of all drug approvals would place the same weight on all drugs whether they are revolutionary therapies such as statins or reformulations of age-old drugs such as aspirin. To alleviate some of this discrepancy it has also become common practice to restrict attention to approvals at the FDA that receive new molecular entity (NME) status. Newly approved drugs receive the NME status if the active moiety has not yet been approved by the FDA, thus providing a strong indication that the therapy has some potential to provide significant welfare improvements.

The count of annual approvals of new molecular entities (NMEs) from 1987 to 2013 was constructed from the Drugs@FDA database ${ }^{7}$. The database does provide information as to the sponsoring firm of each drug approval; however, it is prohibitive to track the "ownership" of any given drug over time given the prevalence of firm- and drug-level acquisitions, as well as licensing and manufacturing agreements. Thus, we do not restrict our sample to any set of firm sponsors. Drugs were matched to each therapeutic category per their primary ATC codes.

\section{$4.2 \quad$ Private R\&D Expenditures}

Estimates of industry-wide investments in pharmaceutical R\&D from 1970 to 2013 were constructed based on annual reports from the Pharmaceutical Research and Manufacturers of American (PhRMA), the industry's lead trade group. PhRMA conducts annual surveys of its member companies and reports summarized results for a number of relevant statistics. Using historical reports ${ }^{8}$, we obtained PhRMA-wide estimates of: total industry R\&D, the share of R\&D allocated to new/innovative product lines (e.g. NMEs), and the share of R\&D allocated across eight major therapeutic categories as outlined in Table A1.

The share of R\&D allocated to NME-type research is not decomposed by therapeutic categories and is reported in only a select number of annual reports 1998-2000. The average

\footnotetext{
${ }^{6}$ Average cost estimates require that we aggregate mean inputs to the eight categories. The main results and directions of effects carry through if we conduct all analyses at the eight category only.

${ }^{7}$ Available at http://www.fda.gov/Drugs/InformationOnDrugs/ucm079750.htm

${ }^{8}$ Reports prior to 2002 are not publicly available, but PhRMA representatives kindly shared copies of annual reports from 1990 to 2001 containing data from as early as 1972 .
} 
reported allocation is $78.3 \%$ and we choose to make the assumption of $80 \%$ for the entirety of our sample period and across each category.

The largest caveat to this data is that therapeutic category-specific investments are not available post-2000. Hence the projection methodology described in the proceeding section. Additionally, because PhRMA underrepresents the industry as a whole we will likely underestimate real industry-wide investments and therefore also underestimate the average cost per NME. So long as any level of misrepresentation is fixed over time, it will not bias our estimates of marginal productivity.

Our final estimate of industry investment must account for the notoriously long development times in this industry- investments in any given year may be related to drugs anywhere from 1 to 15 years away from approval. Based on an average development time of ten to twelve years and an average approval time of at least one year, we sum within-category expenditures from years $t-11$ to $t-1$ to generate our preferred measure. All private investments are deflated using the Biomedical Research and Development Price Index to account for inflation unique to this sector.

\subsection{Exogenous Potential Demand}

In their initial analyses of market size and innovation in the pharmaceutical sector, Acemoglu and Linn (2004) develop a plausibly exogenous measure market size they term "potential demand". This measure utilizes demographic trends to remove the influence of innovation on demand (consumers buying more new products because they are valued) in order to separately identify the influence of demand on innovation (firms developing new products because they expect them to be valued by consumers). The exogenous expected demand $D$ for drug category $j$ at time $t$ is given by

$$
D_{j t}=\sum_{a} I_{a t} \times S_{a j}
$$

where $a$ is a set of 5 -year age bins, $I_{a t}$ is the aggregate national income of individuals in age bin $a$ at time $t$, and $S_{a j}$ is the average share of group $a$ 's income spent on drug category $j$.

Acemoglu and Linn (2004) provide evidence that within-group drug expenditure shares are relatively constant over time while the country's demographics are not. Intuitively, illnesses and the medications used to treat them often effect humans at certain ages (e.g. very few 
people under 45 take statins, but this share increases dramatically with age), so as the income of individuals of certain ages grows, so does the demand for drugs that differentially afflict their age group. Thus, by fixing the expenditure share and only allowing variation in demographics to cause changes in demand, the measure provides a plausibly exogenous measure.

Following Acemoglu and Linn (2004), the income component $I_{a t}$ is constructed from the Current Population Survey (CPS) March supplement and the expenditure component $S_{a j}$ is constructed from the Prescribed Medicine Files of the Medical Expenditure Panel Survey (MEPS). Drug categories are determined based on matching drug names reported in MEPS to their Anatomic Therapeutic Class (ATC) $\operatorname{codes}^{9}$ outlined in Figure 2. ATC codes are structured based on a combination of a drug's mechanisms and the illnesses it is approved to treat. The MEPS data is only available from 1996 to 2013, therefore we extend the $S_{a j}$ measure calculated during this timeframe to our full timeframe of 1985 to 2013. CPS data is available for the full length of our study with all data deflated using the CPI.

\subsection{NIH Investments in Science}

Data on NIH extramural grant awards from 1965 to 2013 was constructed based on data available from the NIH ExPORTER data files as well as a Freedom of Information Act request for data prior to 2000 that is not readily available in the ExPORTER files ${ }^{10}$.

In line with prior research on the allocation of NIH funds (Toole 2012) we employ a keyword based approach to categorizing grants to each of the 16 ATC classes, and further delineate whether or not the grant is obviously "applied" research such as clinical trials, as opposed to basic research aimed at generating new knowledge. By definition, truly "basic" research has the potential to influence all of our therapeutic categories; however, the NIH requires that any grant have some potentially relevant public health implication. So when we refer to "basic" research, we are focusing on research at the NIH that lacks an immediate means of commercialization. This delineation is possible based on keywords as well as examining the grant "Activity Code", which is unique to certain types of grant programs intended to stimulate more applied research, such as the Small Business Innovation Research (SBIR) and Small Business Technology Transfer (STTR) programs. This applied research accounted for roughly $15 \%$ of NIH spending annually. However, these investments were never found to

\footnotetext{
${ }^{9}$ See http://www.whocc.no/atc_ddd_index/ for more information.

${ }^{10}$ Available at http://exporter.nih.gov. Prior to 2000, the total funding amount for each project is absent in the ExPORTER files, hence the FOIA request was necessary.
} 
have a significant relationship with either firm R\&D or drug approvals, so all results below are based on the basic science-only measure of NIH investments.

Much like firm investments, we can imagine that NIH investments in research may take time to influence firm investment decisions or new drug approvals directly. Toole (2012), who used the same data but only the 8 major categories identified the most statistically significant lagflow construction to be the sum of NIH investments 17 to 24 years prior. Using our sixteen categories, we identify significant correlations between lagged flows anywhere in timeframe of 10 to 20 years prior, and based on measures of fit and statistical significance including t-statistics, log-likelihood and Wald chi-square statistic, we identify the flow of NIH spending 15 to 20 years prior as the best predictor of our outcomes of interest. All NIH investments are deflated using the Biomedical R\&D Price Index, which accounts for cost inflation unique to basic biomedical research.

\section{Results}

\subsection{Main Findings}

Table 1 explores very simple production models where NMEs are the outputs and private and public investment are the lagged inputs. The models are estimating using data from the timeframe for which disaggregated private spending is available, 1985-2000. Independently, and ignoring industry-wide trends, both measures of spending are significantly correlated with the approval of NMEs. At the sample means of private R\&D and NIH spending flows and assuming a constant marginal effect, the coefficients from columns (1) and (2) of Table 1 suggest an average marginal cost per NME of $\$ 273$ million and $\$ 976$ million (in real 2012 dollars) for private R\&D and NIH basic science spending, respectively. The private cost per NME is very close to accounting-based studies, which estimated an average cost between \$200-400 million (DiMasi et al. 1991; DiMasi et al. 2003).

This first pass at the cost to the NIH per NME identifies an estimate modestly larger than prior work, such as Toole (2012) who identified an average marginal cost of $\$ 741$ million using an unconditional (no category fixed effects) Poisson model that treated both private and NIH spending as exogenous in the same specification. What is perhaps noteworthy from a policy viewpoint is how large this public investment cost per new drug is relative to private investment, and how large it makes the total cost of bringing a new drug to market, with $\mathrm{NIH}$ spending swamping the magnitude of private spending over which there has been so 
Table 1: NME Production Per Private R\&D and NIH Science, 1985-2000

\begin{tabular}{lcccccc}
\hline \hline & $(1)$ & $(2)$ & $(3)$ & $(4)$ & $(5)$ & $(6)$ \\
\hline & & & & & & \\
Private $\mathrm{R}_{(t-11, t-1)}$ & $0.596^{* * *}$ & & 0.223 & $1.069^{* * *}$ & & $0.763^{* * *}$ \\
& $(0.163)$ & & $(0.265)$ & $(0.246)$ & & $(0.222)$ \\
& & & & & & \\
$\mathrm{NIH}_{(t-20, t-15)}$ & & $0.949^{* * *}$ & $0.828^{*}$ & & $0.812^{* *}$ & 0.759 \\
& & $(0.300)$ & $(0.476)$ & & $(0.395)$ & $(0.477)$ \\
$\operatorname{Time}_{(1989-1992)}$ & & & & 0.0305 & 0.114 & -0.0258 \\
& & & & $(0.134)$ & $(0.150)$ & $(0.142)$ \\
$\operatorname{Time}_{(1993-1996)}$ & & & & -0.171 & 0.167 & -0.256 \\
& & & & $(0.234)$ & $(0.214)$ & $(0.228)$ \\
$\operatorname{Time}_{(1997-2000)}$ & & & & -0.514 & 0.0941 & -0.564 \\
& & & & $(0.403)$ & $(0.320)$ & $(0.381)$ \\
\hline$N$ & 224 & 224 & 224 & 224 & 224 & 224 \\
\hline \hline
\end{tabular}

Note: Standard errors in parentheses, clustered at the drug-category level. Fixed effect (drug category) conditional Poisson specifications. Time dummies are relative to the earliest time period, 1985-1988. All continuous independent variables are log-transformed.* $\mathrm{p}<0.10,{ }^{* *} \mathrm{p}<0.05,{ }^{* * *} \mathrm{p}<0.01$.

much controversy.

As indicated in Section 2, we assume the two major exogenous inputs to the NME production function to be the potential for demand driven by demographic trends and investments in science by the NIH. If these inputs do indeed stimulate private investment in R\&D, or directly result in any NME discoveries (i.e. NIH only), then they should be significantly correlated with NME approvals. Furthermore, we are interested specifically in whether or not these correlations changed significantly at all over the past two and a half decades. If the pharmaceutical industry experienced a significant decline in their productivity during the cost increases post-2000, then this would manifest in significantly lower NME output per changes in demand or NIH investments as it implies the industry was no longer able to convert valuable ideas into new drugs. Figure 4 plots the coefficients of NME counts regressed on these two inputs and uses interactions with the time dummy variables in order to present the trends in NME productivity per potential demand and NIH investments. It is immediately obvious that there is no significant change in the responsiveness of the industry to opportunities created by changes in either consumer demand or the supply of basic science. The estimated magnitudes of the elasticity of NME approvals with respect to changes in potential demand are very similar to the coefficients estimated in Acemoglu and Linn (2004) initial development of that measure. A number of related studies have investigated the 


\section{Figure 4: Trends in NME output per potential demand and NIH basic science, 1987-2013}
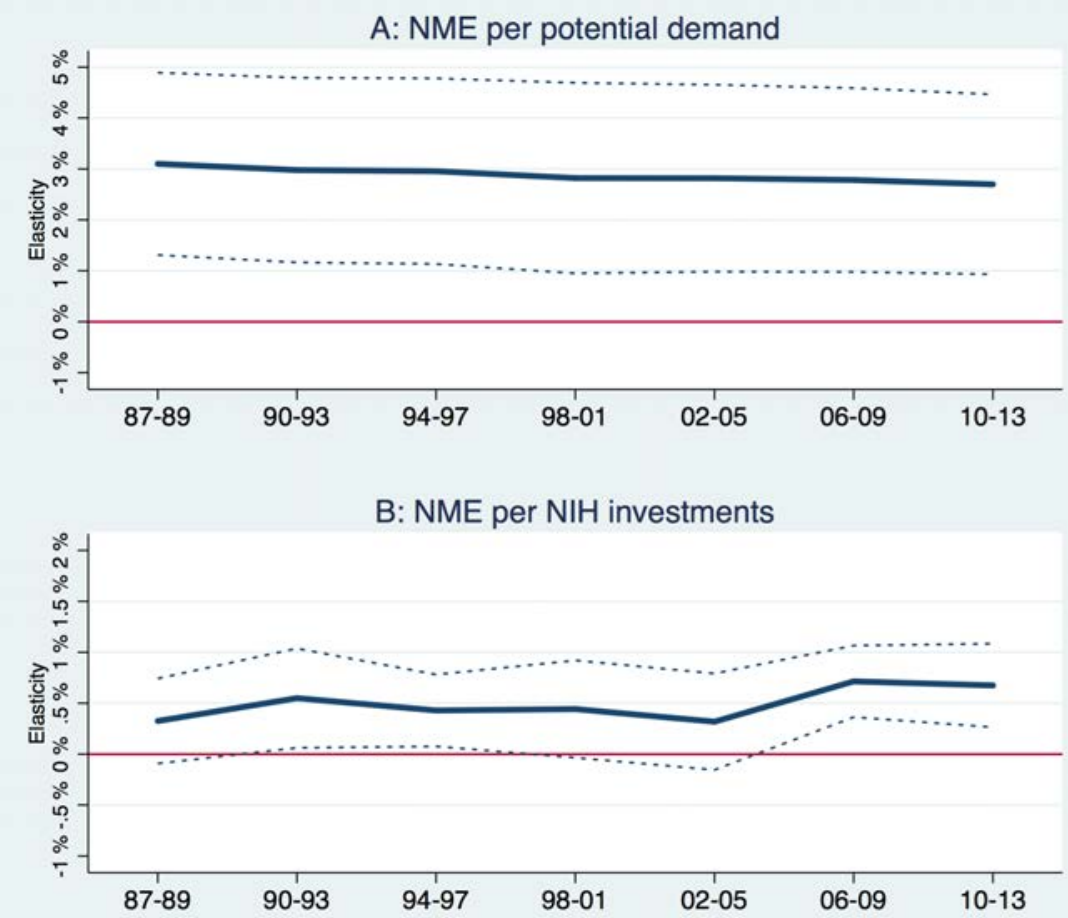

Note: Potential demand is per the exogenous market size measure and NIH investments are a sum of lagged investments in basic science; both measures are described in Section 4. Coefficients are plotted from the same conditional Poisson model of the count of NMEs regressed on drug-class specific demand and NIH measures interacted with each time dummy variable. Non-interacted time dummies are also included in the model to capture variation across all drug classes over time.

elasticity of pharmaceutical innovations with respect to changes in demand using a variety of methods to identify exogenous changes in demand and measures of innovation. Our results and estimated magnitudes fit squarely in line with this previous work ${ }^{11}$.

\footnotetext{
${ }^{11}$ Finkelstein (2004) explores a policy change related to the expected value of certain vaccines and finds a $1 \%$ increase in expected market size stimulates a $2.5 \%$ increase in the number of clinical trials for affected diseases. Duggan and Morton (2010) and Blume-Kohout and Sood (2013) utilize the enactment of Medicare Part D as a plausibly exogenous shock to consumers' willingness to pay for pharmaceuticals and also find corresponding increases in clinical trials for drug categories expected to grow the largest following Part D's enactment. In closely related work, Dubois et al. (2015) utilize detailed global revenue data and instrumental variables approach to estimate this elasticity. Directly comparing their estimates with ours is not straightforward given the different data sources and measures of demand; however, we can get a sense of consistency by comparing the estimating change in demand necessary to induce a new NME. At the sample means, our estimates imply that roughly $\$ 1.2$ billion is necessary, with Dubois et al. (2015) finding that $\$ 2.5$ billion is necessary, despite their elasticity estimate being an order of magnitude less than ours (0.25 versus 3.0). We
} 
The elasticities for NIH investments are at times not significantly different from zero; however, taken altogether the trend indicates a relatively stable relationship that, if anything, has improved in the past decade. This finding in the aggregate that NIH investments generate valuable downstream outcomes has received support from Azoulay et al. (2015) who use more fine-grain data and careful econometric techniques.

\section{Table 2: Private R\&D Investments per NIH and potential demand, 1985-2000}

\begin{tabular}{lccc}
\hline \hline & $(1)$ & $(2)$ & $(3)$ \\
\hline Potential Demand & $1.556^{* * *}$ & & $1.366^{* * *}$ \\
& $(0.221)$ & & $(0.210)$ \\
& & $0.361^{* * *}$ & $0.311^{* * *}$ \\
$\mathrm{NIH}_{(t-20, t-15)}$ & & $(0.0901)$ & $(0.0914)$ \\
& & & \\
$\operatorname{Time}_{(1989-1992)}$ & $0.201^{* * *}$ & $0.245^{* * *}$ & $0.157^{* * *}$ \\
& $(0.0230)$ & $(0.0347)$ & $(0.0351)$ \\
& & & \\
Time $_{(1993-1996)}$ & $0.454^{* * *}$ & $0.563^{* * *}$ & $0.360^{* * *}$ \\
& $(0.0306)$ & $(0.0556)$ & $(0.0565)$ \\
Time $_{(1997-2000)}$ & $0.487^{* * *}$ & $0.836^{* * *}$ & $0.401^{* * *}$ \\
& $(0.0523)$ & $(0.0825)$ & $(0.0806)$ \\
\hline$N$ & 224 & 224 & 224 \\
adj. $R^{2}$ & 0.883 & 0.881 & 0.899 \\
\hline \hline
\end{tabular}

Note: Standard errors in parentheses, clustered at the drug-category level. Fixed effect (drug category) OLS specifications. Time dummies are relative to the earliest time period, 1985-1988. All continuous variables are log-transformed. * $\mathrm{p}<0.10,{ }^{* *} \mathrm{p}<0.05,{ }^{* * *} \mathrm{p}<0.01$.

These results also provide support for the first stage of our model - that changes in these inputs are the major forces spurring industry investment. To explore this relationship specifically, Table 2 presents the results of estimating equation (2) using OLS with drug-class fixed effects and time dummies. Because this disaggregated data on private R\&D is only available pre-2001 we can only estimate the equation for this portion of our timeframe. Within this period, we find evidence that our measures of demand and NIH investments are both significantly correlated with investments by the pharmaceutical industry.

The magnitudes of the coefficients suggest that for each $10 \%$ increase in the potential market size of a drug-class for a given year, the industry will have invested $14 \%$ more into R\&D. Likewise, for each $10 \%$ increase in NIH investments in the years prior, the industry will invest $3 \%$ more into R\&D. Relatively speaking, it appears that the pharmaceutical industry

consider these estimates to be relatively consistent given the differences in sample periods and the fact that we lack data on worldwide revenues. 
is significantly more responsive to changes in demand compared to changes in the supply of science. However, as noted earlier, the magnitude of NIH investments relative to the market sizes is much larger - directly comparing these relative elasticities should be done so with this in mind.

The time dummies in these models also indicate that aside from our two measures, there also appears to have been a significant increase in $R \& D$ investments over this timeframe with roughly $40 \%$ larger investments observed in the late 1990's compared to the late 1980's, conditional on our inputs and fixed differences across the drug classes. And notably, these models explain upwards of $90 \%$ of the variation in R\&D investments within each drug class, supporting our assumption that these are likely the major drivers of R\&D investment decisions in this industry.

Given the stability and significance of our model of private R\&D determinants, we use the estimates from this first stage in order to project out predicting spending post-2000 under the assumption that the relationships identified in Table 2 column (3) persist. The result of these linear projections are aggregated to industry total annual investments and compared to the observed data (see Figure 1). Our model appears to predict R\&D investments reasonably well in the post-2000 period where we observe only inputs and not actual category-specific investments. But notably, our model regularly underpredicts investments in this period on the order of $20-30 \%$. In a later section, we speculate that this may be due to entry drawing down above normal economic profits.

Table 3 presents the results from re-estimating the models presented in Table 1 where private $R \& D$ was assumed endogenous and the data was limited to pre-2001. Comparing the coefficients on our predicted $R \& D$ measure to the coefficients on the time dummies allows us to examine whether any changes in productivity appeared to occur for marginal or average investments, respectively. Our predicted R\&D measure is significantly correlated with NME output, and per column (3) this relationship did not appear to change significantly during the so-called crisis of the 2000's.

Rather, it appears that the significant declines in NME output occurred for the average idea as the time dummies for NME outputs post-2000 are significantly less than zero. In other words, the estimates indicate that after 2000, across all therapeutic categories, the average rate of NME approvals was roughly $150 \%$ lower than before.

Certainly we are not the first to identify this decline in approvals conditional on observed investments. However, the important point and major contribution of this paper is that these results imply the declines were amongst the average drug discovery project and not the 
Table 3: NME Production with Endogenous Investments, 19852013

\begin{tabular}{|c|c|c|c|c|}
\hline & $(1)$ & $(2)$ & $(3)$ & (4) \\
\hline Pred. $R \& D_{(t-11, t-1)}$ & $\begin{array}{c}1.796^{* * *} \\
(0.549)\end{array}$ & & $\begin{array}{c}1.799^{* * *} \\
(0.539)\end{array}$ & $\begin{array}{c}1.963^{* * *} \\
(0.747)\end{array}$ \\
\hline NIH $\operatorname{Basic}_{(t-20, t-15)}$ & & $\begin{array}{c}0.459^{* *} \\
(0.223)\end{array}$ & & $\begin{array}{c}-0.0869 \\
(0.331)\end{array}$ \\
\hline $\begin{array}{l}\text { Pred. } \operatorname{R\& D}_{(t-11, t-1)} \\
\times 2001-\text { on }\end{array}$ & & & $\begin{array}{r}-0.0191 \\
(0.232)\end{array}$ & \\
\hline Time $_{89-92}$ & $\begin{array}{l}-0.0962 \\
(0.164)\end{array}$ & $\begin{array}{c}0.183 \\
(0.131)\end{array}$ & $\begin{array}{r}-0.0970 \\
(0.163)\end{array}$ & $\begin{array}{l}-0.111 \\
(0.162)\end{array}$ \\
\hline Time93-96 & $\begin{array}{l}-0.237 \\
(0.276)\end{array}$ & $\begin{array}{c}0.304 \\
(0.189)\end{array}$ & $\begin{array}{l}-0.239 \\
(0.272)\end{array}$ & $\begin{array}{l}-0.268 \\
(0.274)\end{array}$ \\
\hline Time $_{97-00}$ & $\begin{array}{l}-0.701 \\
(0.479)\end{array}$ & $\begin{array}{c}0.263 \\
(0.298)\end{array}$ & $\begin{array}{l}-0.704 \\
(0.473)\end{array}$ & $\begin{array}{l}-0.768 \\
(0.478)\end{array}$ \\
\hline Time $_{01-04}$ & $\begin{array}{c}-1.183^{* *} \\
(0.520)\end{array}$ & $\begin{array}{c}-0.00462 \\
(0.278)\end{array}$ & $\begin{array}{l}-0.742 \\
(5.523)\end{array}$ & $\begin{array}{c}-1.264^{* *} \\
(0.523)\end{array}$ \\
\hline Time $_{05-08}$ & $\begin{array}{c}-1.699 * * * \\
(0.517)\end{array}$ & $\begin{array}{l}-0.312 \\
(0.268)\end{array}$ & $\begin{array}{l}-1.255 \\
(5.553)\end{array}$ & $\begin{array}{c}-1.793^{* * *} \\
(0.528)\end{array}$ \\
\hline Time $_{09-13}$ & $\begin{array}{c}-1.550^{* * *} \\
(0.587)\end{array}$ & $\begin{array}{c}-0.0418 \\
(0.338)\end{array}$ & $\begin{array}{l}-1.105 \\
(5.550)\end{array}$ & $\begin{array}{c}-1.652^{* * *} \\
(0.595)\end{array}$ \\
\hline$N$ & 464 & 464 & 464 & 464 \\
\hline Period & Full & Full & Full & Full \\
\hline
\end{tabular}

Note: Standard errors in parentheses, clustered at the drug-category level. Fixed effect (drug category) conditional Poisson specifications. Time dummies are relative to the earliest time period, 1985-1988. All independent continuous variables are log-transformed. Predicted $R \& D$ is the linear projection of private $R \& D$ investments based on the correlations from Table 2, Column (3), without timeperiod dummies since they are not identified in the post-2000 timeframe. ${ }^{*} \mathrm{p}<0.10$, ${ }^{* *} \mathrm{p}<0.05,{ }^{* * *} \mathrm{p}<0.01$. 
marginal project. As argued in Section 2, this distinction has important policy implications. Our results do not point to any significant difference in this industries' ability to turn the next (marginal) idea into a valuable drug, relative to what was observed in decades prior. Rather, it appears that the average expected costs of operating in this industry are what increased.

Referring back to Figure 2, this indicates that the distribution of ideas is relatively linear and that as forces of supply (NIH science) and demand (demographic trends) increase the value of the marginal drug idea, firms are willing to incur higher average costs in order to continue to produce profits. While we cannot directly connect our results to changes in social welfare, this result implies that, should policymakers seek to increase the rate at which new drugs are introduced, policies should focus on decreasing the fixed costs common to all new drug ideas. These costs might include efforts such as establishing clinical trial networks across the country (or globe), or the ability to access new results from publicly funded biomedical research.

\subsection{Explaining the Increase in Investments beyond the NIH and Demand}

Recall from Figure 1 that, while our model of R\&D was able to relatively accurately predict the trend in investments, it appears we under-predict investments for the majority of years post-2000, typically on the order of 20-30\%. As argued previously, this "overinvestment" (relative to the expected response to NIH investments and shifts in demand) stands in contrast to a growth supply-side frictions that prior literature has frequently suggested ${ }^{12}$. If firms were truly faced with new problems in their governance, or regulations became suddenly more burdensome, this should have been met with a slower growth in R\&D costs (relative to pre-2000) as markets grew. In contrast, our regressions indicate that the marginal idea (as proxied by marginal R\&D spending) resulted in the same number of NMEs in expectation after 2000 compared to before (See Table 2, Column 3). Likewise, Figure 4 indicates a very stable relationship between changes in the demand of new drugs and the rate of new drug approvals.

Instead we propose two alternatives ${ }^{13}$ : (1) the growing value of health, and (2) competing

\footnotetext{
${ }^{12}$ We are agnostic to stable frictions that may exist on the supply-side in this market, such as the "shorttermism" of managers discussed by Budish et al. (2015) or the effect of regulatory requirements at the FDA. We are only concerned with whether changes in the effects of these frictions might be responsible for the growth in $\mathrm{R} \& \mathrm{D}$ costs observed.

${ }^{13}$ The introduction of Medicare Part D in 2003 should also be noted. The demand measure does not
} 
away of supranormal profits. To the first point, while the Acemoglu and Linn (2004) measure of potential demand is empirically useful in that it identifies plausibly exogenous shifts in demand, it assumes that the elasticity of health spending with respect to income is fixed at one. Thus, the value of health to each individual is held constant. Hall and Jones (2007) present and solve a detailed model of health investment and production which, upon solving numerically, implies an elasticity significantly greater than $1^{14}$. These magnitudes imply that our measure underestimates changes in demand at times of income growth, hence the underpredictions of our full model. However, micro-level evidence has yet to provide robust support for elasticities much greater than one (Acemoglu et al. 2013), and so we are reluctant to propose this mechanism as being fully responsible for our finding.

Our second proposed mechanism is based on the notion that, in industries such as this, the enormous barriers to entry will prevent new firms from immediately competing away excess returns (relative to other industries). The appearance of supranormal profits being a key feature of this industry prior to 2000 has been highlighted previously, and it was hypothesized that new entry should eventually bid these returns down to levels seen in other industries (Scherer 2001; Danzon 2011). In order to explore trends in industry profits, Figure 5 plots two measures of profitability using PhRMA reported sales and R\&D investment data: (1) annual revenues per "on-patent" NMEs, and (2) annual revenues per prior R\&D investments. The first measure speaks to the value of new drugs. We define "on-patent" NMEs as those approved by the FDA in the ten years prior to the focal year, given the average length of patent protection post FDA approval ${ }^{15}$. Prior to 2000, the average revenues per on-patent NME was relatively stable at roughly $\$ 625$ million per year per drug. A noticeable increase in the value of these drugs is obvious, beginning around 2000 and continuing to our most recent data, reaching nearly $\$ 1$ billion per year per drug.

Conversely, the trend in revenues per R\&D investments - a measure indicative of overall industry profitability - suggests a significant decline in overall returns. Prior to 2000 the data indicates that each dollar of $R \& D$ was generating upwards of six dollars in future revenues, even after accounting for the capitalization of costs during the long development

perfectly capture the portion of growth in potential market size driven by this major policy. In order to maintain exogeneity, it holds age-category by drug-category expenditure shares $\left(S_{j t}\right.$ in eq. 1$)$ fixed based on the sample average which includes seven years prior to Part D's introduction. Thus, therapeutic categories that experience the largest growth in utilization by Part D eligible individuals likely underestimate true growth in demand post-2003.

${ }^{14}$ Depending on their method of solving for the elasticity and the assumptions involved, Hall and Jones' (2007) point estimates range between 1.5 and 2.

${ }^{15}$ This simplifying definition is useful because connecting individual patents to individual molecules is not a straightforward exercise as multiple patents may cover a single "drug", which may also hold different market exclusivities (either via a patent of FDA policy) for different indications. 


\section{Figure 5: Trends in revenues per drugs and R\&D expendi- tures, 1985-2012}

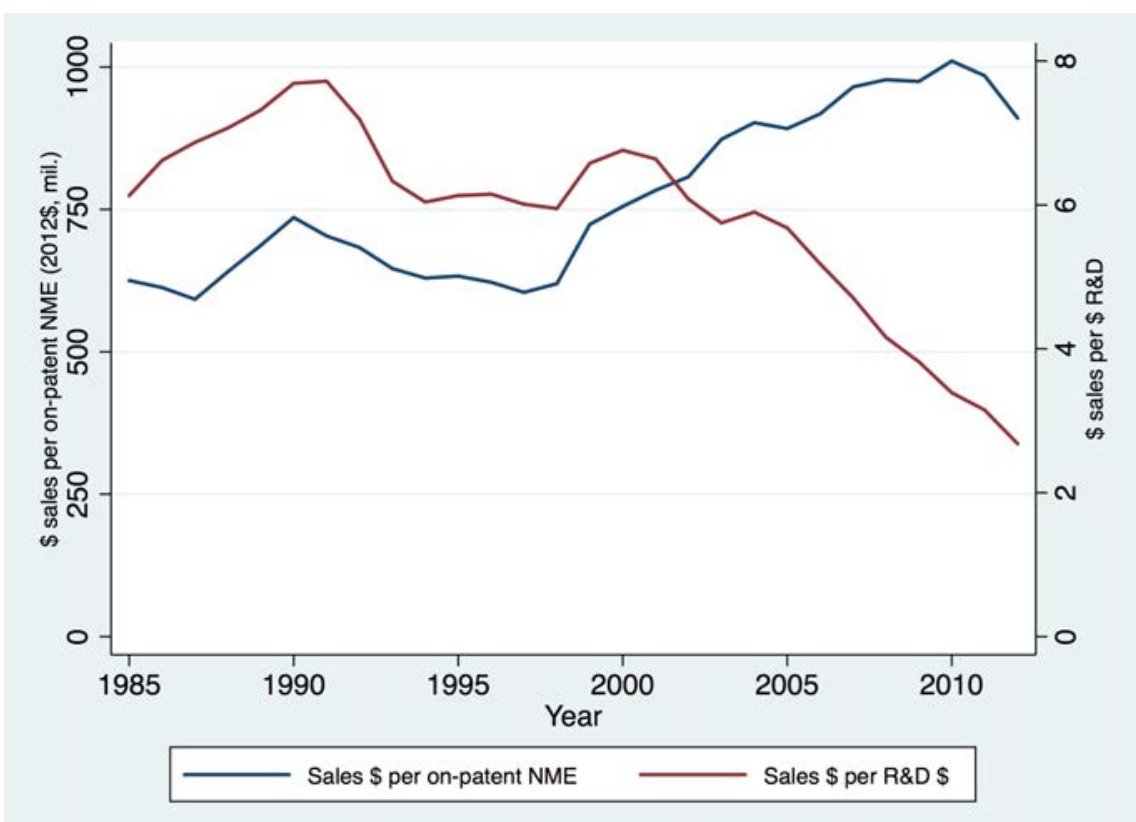

Note: Sales are US-based revenues. On-patent NME refers to New Molecular Entities approved in the 10 years prior. R\&D investments are lagged 10 years relative to the reported year, and are capitalized using a $10 \%$ annual interest rate. Based on data in PhRMA Annual Reports and FDA new drug approvals.

times (assumed here to be 10 years on average). Certainly our measure of costs is not perfectly comprehensive: only "R\&D" costs are reported in the PhRMA data. Still, this magnitude of returns to capital, even under generous assumptions about unmeasured $\operatorname{costs}^{16}$, is objectively large.

But after 2000, the return to $R \& D$ has essentially halved while the average returns for each new drug has increased by roughly $30 \%$. This pattern of lower overall returns even amidst increasingly valuable (based on revenue per product) products is in line with the notion competitive pressures decreased profit margins even as the demand for new drugs continued to grow. A full-fledged analysis of competition in this industry is beyond the scope of this paper, so we only offer some speculations as to why these returns were so excessive in

\footnotetext{
${ }^{16}$ Data on industry-wide non-R\&D expenditures is not readily available. Arguably, aside from $R \& D$ the industry's largest expenditures may be in the form of physician-based payments via detailing or other interactions. Reports from the Open Payments function of the Center for Medicare and Medicaid services indicate that in between 2013 and 2015, roughly $\$ 3$ to $\$ 7$ billion was paid to physicians in some form (e.g. meals, travel, education) annually (Source: openpaymentsdata.cms.gov). Relative to approximately $\$ 50$ billion in annual R\&D investments, these additional costs would not substantially alter the magnitude of returns presented in Figure 5.
} 
earlier periods. Many observers have noted the growth in entrepreneurial firms engaging in biomedical research, which is likely a function of decreasing fixed costs of R\&D prior to clinical trials. Others have argued that the financial arrangements unique to the healthcare sector have given rise to a "medical innovation premium" (Koijen et al. 2016), which may be declining over time as the uncertainties surrounding new drug production become resolved in the long-run.

\section{Conclusion}

This paper introduces an alternative perspective on the productivity changes observed in the pharmaceutical industry over the past twenty years. The traditional view has taken firm R\&D investments as given, and speculated about what supply-side frictions have arisen to cause the declines in productivity - drugs per R\&D dollar - observed. In contrast, we take the amount invested (and expectations of success and profits) as endogenous, and suggest why firms would pursue less productive investments in a world of fixed resources (i.e. new drug ideas). We attribute this pursuit in large part to a documented growth in the demand for new products and fluctuations in NIH spending that increased the returns to the marginally profitable drug idea. Much like the farmers studied by Ricardo, pharmaceutical firms appeared willing to take on increased costs given expectations of increased demand productivity declines were a profitable choice, not a worrisome problem.

We motivate our analyses with a simplified production function that accounts for this endogeneity of R\&D investments. Although, the data requires that we analyze relatively aggregate categories of investments across therapeutic classes. In particular, our estimates imply that the marginal value of new drug ideas has not changed significantly over the past thirty years, while the average value of these ideas did decline substantially post-2000. These results suggest that policies intent on stimulating further innovation in this industry may be most effective when designed to lower the fixed costs of R\&D shared by all active R\&D projects, such as establishing clinical trial networks, as opposed to subsidizing marginal expenditures with tax credits.

Examining trends in revenues and costs more generally, we also speculate that industry-wide profitability was above normal prior to 2000 - a feature documented previously (Danzon 2011) - so new investment at lower (but still positive) marginal profit was the result of entry (eventually) bidding down returns. We think this view places less emphasis on the idea that there is something on the supply side that needs to be "fixed" (by changes in firm strategies, 
trial design, or new institutes of health) and more emphasis on a natural economic model of investment where transitions between equilibria, during which profits are supranormal, takes time. Looking forward, if the demand for new drugs continues to grow, and there is cause to think it will (a la Hall and Jones 2007), and there is not a major boost to NIH investments, we expect continued declines in the number of new drugs per R\&D dollar, but do not see this a case for major policy interventions or concern. 


\section{References}

Acemoglu, D., Finkelstein, A., and Notowidigdo, M. J. (2013). Income and health spending: Evidence from oil price shocks. Review of Economics and Statistics, 95(4):1079-1095.

Acemoglu, D. and Linn, J. (2004). Market size in innovation: Theory and evidence from the pharmaceutical industry. The Quarterly journal of economics, 119(3):1049-1090.

Azoulay, P., Zivin, J. S. G., Li, D., and Sampat, B. N. (2015). Public r\&amp;d investments and private-sector patenting: evidence from nih funding rules. Technical report, National Bureau of Economic Research.

Blume-Kohout, M. E. and Sood, N. (2013). Market size and innovation: Effects of medicare part d on pharmaceutical research and development. Journal of public economics, 97:327336.

Blundell, R., Griffith, R., and Windmeijer, F. (2002). Individual effects and dynamics in count data models. Journal of Econometrics, 108(1):113-131.

Budish, E., Roin, B. N., and Williams, H. (2015). Do firms underinvest in long-term research? evidence from cancer clinical trials. The American economic review, 105(7):2044-2085.

Danzon, P. M. (2011). The economics of the biopharmaceutical industry. In Glied and Smith (eds), The Oxford Handbook of Health Economics (Oxford, 2011), pages 520-554.

DiMasi, J. A., Hansen, R. W., and Grabowski, H. G. (2003). The price of innovation: new estimates of drug development costs. Journal of health economics, 22(2):151-185.

DiMasi, J. A., Hansen, R. W., Grabowski, H. G., and Lasagna, L. (1991). Cost of innovation in the pharmaceutical industry. Journal of health economics, 10(2):107-142.

Dubois, P., de Mouzon, O., Scott-Morton, F., and Seabright, P. (2015). Market size and pharmaceutical innovation. The RAND Journal of Economics, 46(4):844-871.

Duggan, M. and Morton, F. S. (2010). The effect of medicare part d on pharmaceutical prices and utilization. The American Economic Review, 100(1):590-607.

Finkelstein, A. (2004). Static and dynamic effects of health policy: Evidence from the vaccine industry. The Quarterly Journal of Economics, 119(2):527-564.

Hall, R. E. and Jones, C. I. (2007). The value of life and the rise in health spending. Technology, 39. 
Koijen, R. S., Philipson, T. J., and Uhlig, H. (2016). Financial health economics. Econometrica, 84(1):195-242.

Kola, I. and Landis, J. (2004). Can the pharmaceutical industry reduce attrition rates? Nature reviews Drug discovery, 3(8):711-716.

Scannell, J. W., Blanckley, A., Boldon, H., and Warrington, B. (2012). Diagnosing the decline in pharmaceutical r\&amp;d efficiency. Nature reviews Drug discovery, 11(3):191-200.

Scherer, F. M. (2001). The link between gross profitability and pharmaceutical r\&amp;d spending. Health Affairs, 20(5):216-220.

Toole, A. A. (2012). The impact of public basic research on industrial innovation: Evidence from the pharmaceutical industry. Research Policy, 41(1):1-12. 


\section{Appendix}

\section{Table A1: Drug Category Crosswalk}

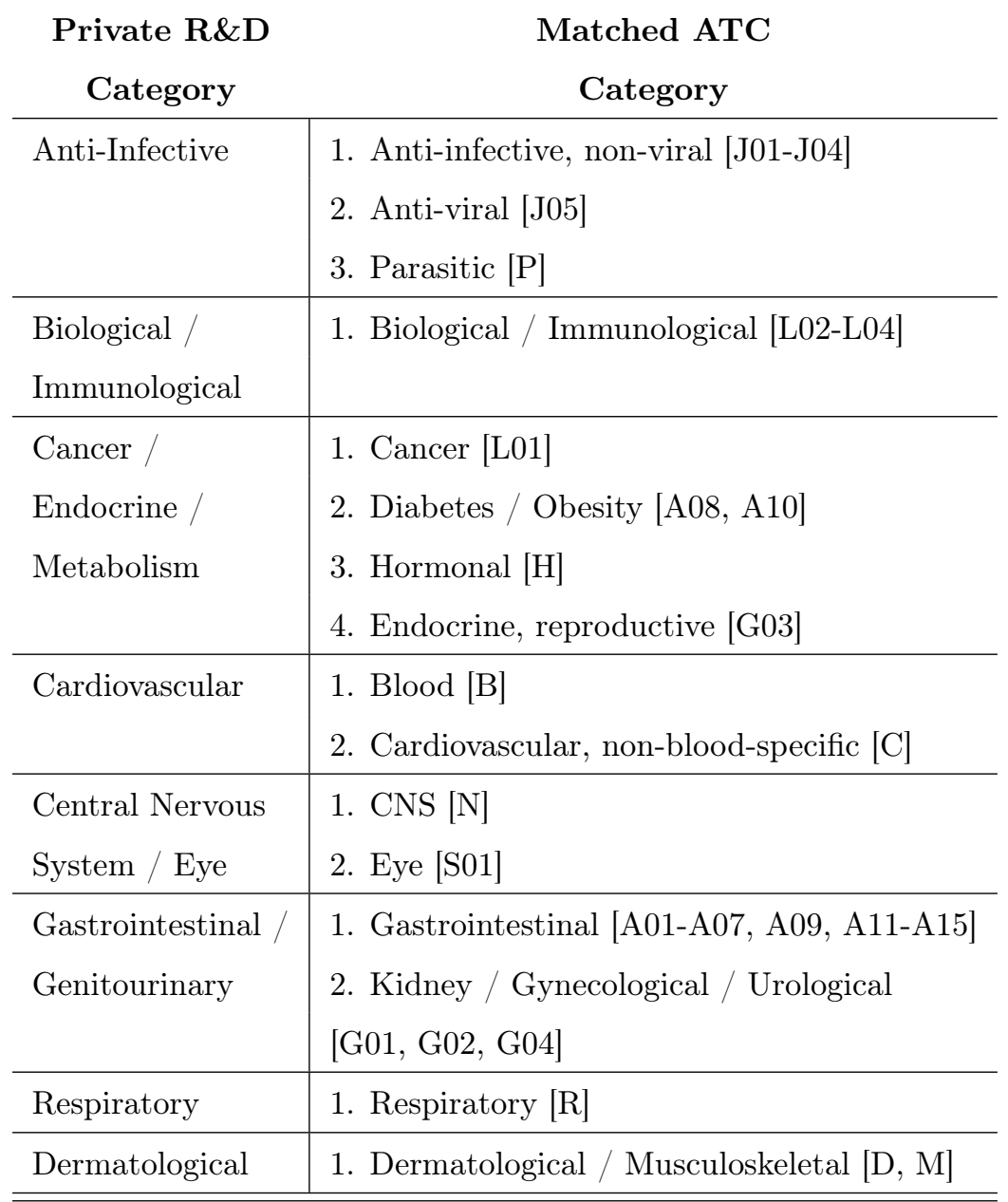

Note: Private R\&D categories are the most disaggregated levels of research and development investments reported in historical PhRMA reports. Anatomical Therapeutic Chemical Classification System (ATC) categories are used to classify drugs in the drug approval and utilization (demand) data. 